\title{
Notas sobre mudança estrutural na indústria brasileira: \\ Uma comparação internacional
}

\section{Introdução}

\author{
Fábio Scatolin* \\ Gabriel Porcile** \\ Wellington Pereira***
}

Define-se mudança estrutural na indústria como as mudanças na participação dos distintos setores no valor adicionado total da indústria manufatureira. A literatura sugere que a mudança estrutural na direção de setores intensivos em tecnologia e de maior elasticidade renda da demanda é desejável para sustentar o crescimento e a competitividade de longo prazo da economia (CEPAL, 2004; Cimoli et al, 2005; UNCTAD, 2005). A seguir analisa-se a relação entre um indicador de qualidade da estrutura produtiva e alguns indicadores de desempenho econômico. Como indicador do grau de diversificação e densidade tecnológica da estrutura produtiva será usado o Índice de Krugman, definido como:

(1) $I K_{j}=\sum_{i=1}^{i=n}|X i j-X i R|$

$X_{i j}$ representa a participação do setor $i$ no valor adicionado da indústria manufatureira do país $j$, enquanto $X_{i R}$ é essa mesma participação no país $R$ usado como referência ou benchmark. O país de referência é os Estados Unidos. O IK é a soma de todas as diferenças em módulo da participação no valor adicionado manufatureiro entre o país analisado e o país de referência. Quanto maior o índice $I K$, maior a diferença com relação à estrutura dos Estados Unidos. O $I K$ pode adotar qualquer valor entre zero e 2, sendo que o zero indica perfeita coincidência de estruturas, enquanto que um valor igual a 2 indica que os dois países não teriam nenhum setor industrial em comum. Assume-se que a tendência desejável da mudança estrutural é no sentido de reduzir o IK.

Usar a estrutura industrial dos Estados Unidos como referência de uma economia já amadurecida, líder em termos tecnológicos, não é uma escolha livre de problemas. Por um lado, a economia norte-americana não é líder em todos os setores industriais. Por outro lado, nem todas as economias desenvolvidas devem necessariamente mostrar a mesma estrutura industrial que os Estados Unidos. Diferenças na dotação de fatores, nas políticas e na própria trajetória produtiva anterior implicam variações estruturais que não necessariamente refletem

\footnotetext{
* Professor do Departamento de economia da UFPR. Endereço eletrônico: scatolin@ufpr.br

** Professor do Departamento de economia da UFPR. Endereço eletrônico: porcile@ufpr.br

*** Mestre em Desenvolvimento Econômico (UFPR) e Analista do Banco Regional de Desenvolvimento do Extremo Sul (BRDE). Endereço eletrônico: wdspereira@yahoo.com.br
} 
maior vulnerabilidade ou menor capacidade tecnológica. No entanto, entende-se que quando as diferenças estruturais são marcadas, elas indicam uma capacidade menor de aprendizado, de aumento da produtividade e de crescimento.

\section{IK e competitividade tecnológica}

Analisa-se a relação entre o IK e um indicador "puro" do nível tecnológico dos países, o indicador ARCO sugerido por Archibugi e Cocco (2004). Esse indicador é construído a partir de uma média de três indicadores (ponderados no valor final do índice com o mesmo peso): um indicador de produção científica e tecnológica ( $I a)$, um indicador de capital humano (Ib) e um indicador de infra-estrutura de ciência e tecnologia (Ic):

$$
\operatorname{ArCo}=\frac{1}{3}(I a+I b+I c)
$$

$\mathrm{O}$ indicador Ia inclui duas variáveis: número de patentes nos Estados Unidos e número de trabalhos científicos publicados por habitante; $I b$ inclui taxa de analfabetismo, número médio de anos de estudo e número de matriculados em cursos de engenharia e ciências em nível terciário como percentagem da população; Ic combina a difusão dos serviços de Internet, dos serviços telefônicos e do consumo de energia elétrica.

O gráfico 1 mostra a relação entre o IK e o indicador ArCo. Como era esperado, há uma forte relação negativa entre os dois indicadores: estruturas produtivas menos densas estão associadas a menores capacidades tecnológicas. Observe-se que não se está afirmando que uma estrutura industrial mais diversificada leve automaticamente a maiores capacidades tecnológicas, nem que a causalidade ocorre em sentido inverso (das capacidades para a estrutura). O que o gráfico indica é que as duas variáveis mostram uma forte associação positiva. Muito provavelmente, o sentido da causalidade seja bidirecional e exista uma interação muito forte entre ambas, característica dos círculos virtuosos de aprendizado.

É interessante ressaltar que o Brasil mostra capacidades tecnológicas inferiores à média, dado seu nível de diversificação. O inverso ocorre com Austrália e Noruega, o que provavelmente reflete diferenças chave no nível dos investimentos realizados em capital humano e nas instituições de P\&D. Argentina e México também mostram valores inferiores à média, embora isso seja menos grave na Argentina. 
Gráfico 1. Estrutura industrial e capacidade tecnológica

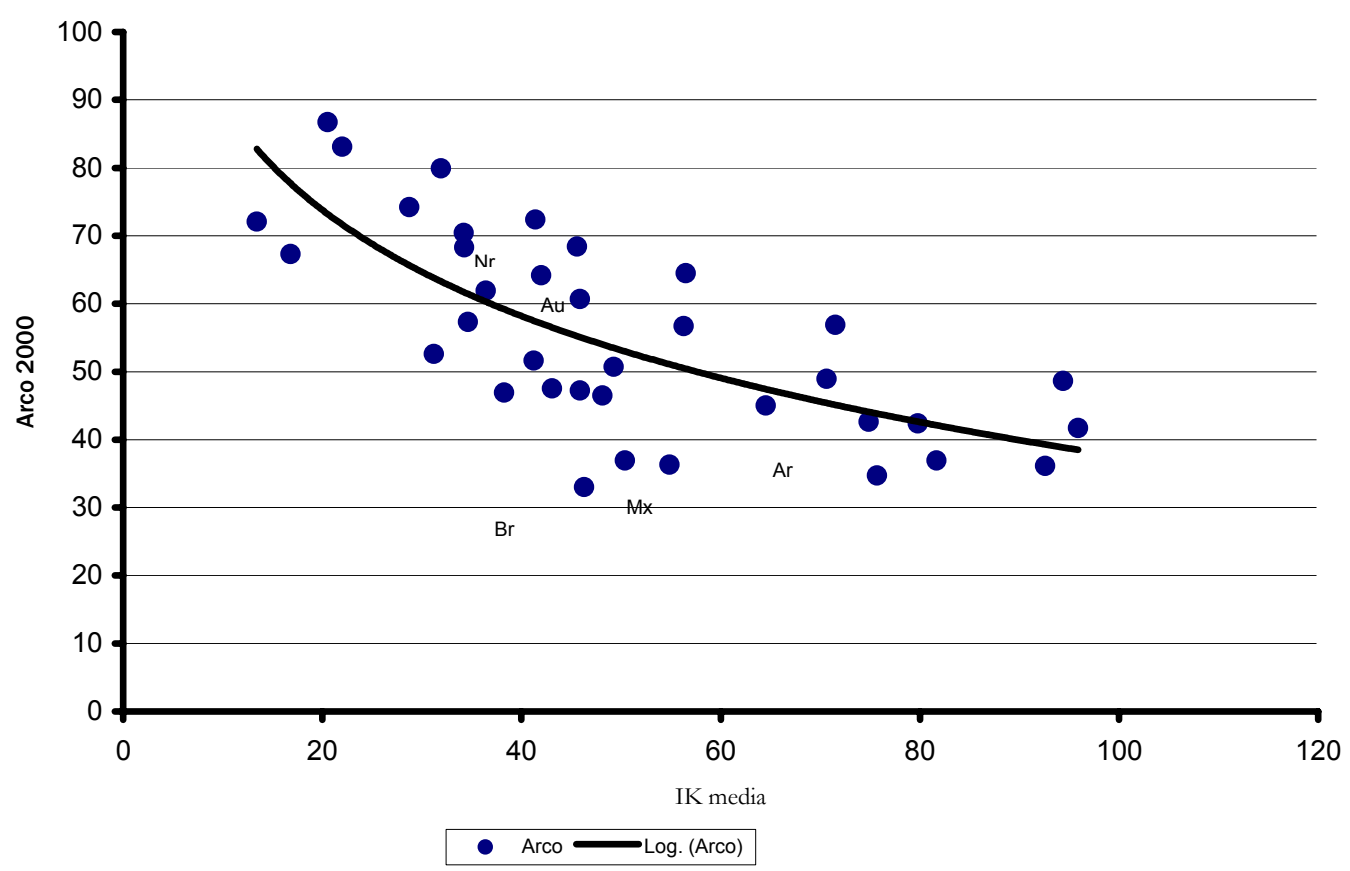

Fonte: os autores a partir de dados da Unido e de Archibugi e Cocco (2004)

A diversificação industrial e as capacidades tecnológicas importam porque elas estão relacionadas à produtividade, à renda per capita e, portanto, ao bem-estar. O gráfico 2 ilustra a relação entre estrutura produtiva e renda per capita. É possível observar no gráfico que o Brasil tem um nível de renda per capita inferior ao que corresponderia a seu grau de desenvolvimento produtivo. Isso é compatível com o que já foi observado com relação ao indicador ArCo. É interessante, também, reparar no ponto fora da linha, o outlier no canto superior direito do gráfico. Esse país é Luxemburgo, que por razões muito específicas, não requer ampliar suas capacidades produtivas para alcançar um elevado padrão de vida. O gráfico 3, por sua vez, mostra que existe uma associação negativa muito intensa entre exportações de bens de alta tecnologia e o índice IK. 
Gráfico 2. PIB per capita e estrutura industrial

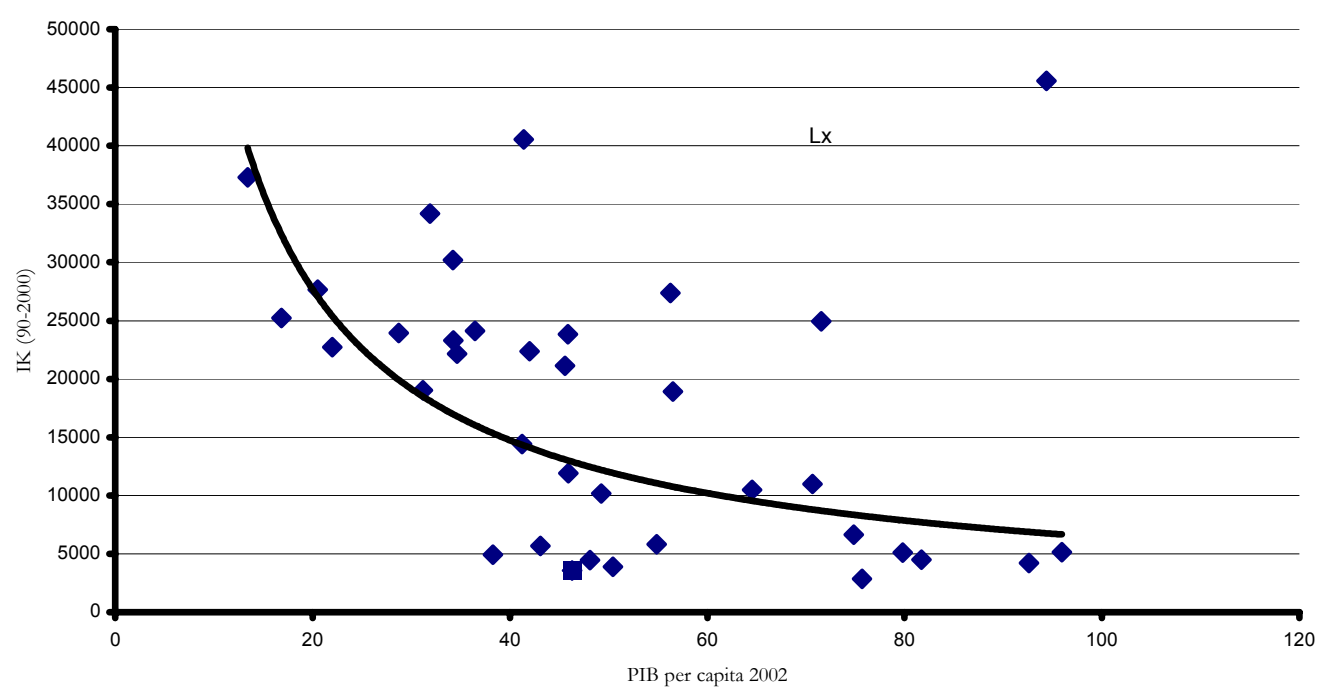

- PIBpc 2002 Potência (PIBpc 2002)

Fonte: os autores a partir de dados da Unido

Gráfico 3. Exportações de alta tecnologia e estrutura industrial

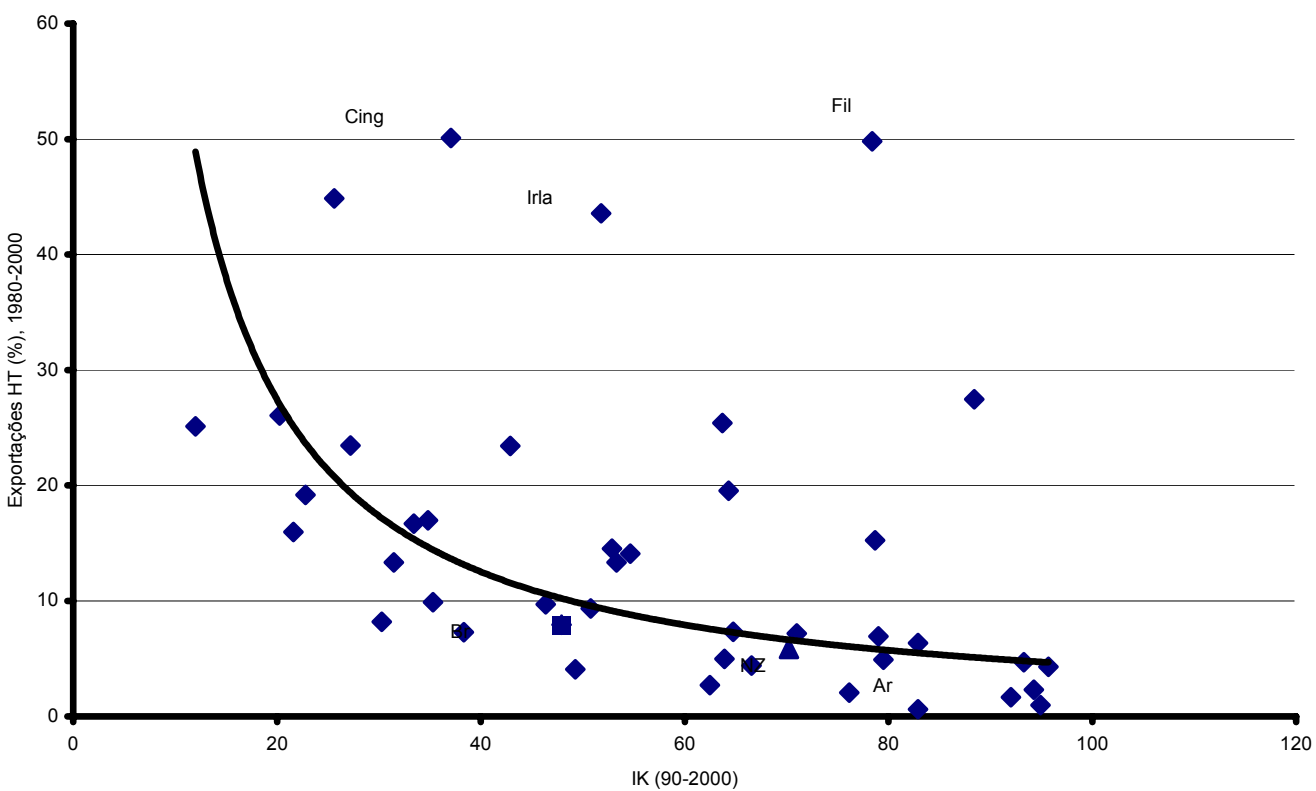

Fonte: os autores a partir de dados da Unido e do World Bank 


\section{Evolução da estrutura industrial}

Outro aspecto que interessa é em que medida as diferenças na estrutura produtiva entre os países tendem a aumentar ou diminuir no tempo. O gráfico 4 mostra os valores médios do índice IK em dois períodos, 1970-82 e 1990-2000. Países abaixo da linha de $45^{\circ}$ são países para os quais o IK aumentou entre os dois períodos, mostrando, portanto, divergência estrutural. Inversamente, países acima dessa linha passaram por processos de mudança estrutural, que levaram à diversificação produtiva e a uma maior aproximação com as economias industriais. Claramente, a economia brasileira encontra-se no grupo daquelas em que a mudança estrutural foi menos intensa, ao contrário do que ocorreu nos países asiáticos e alguns países europeus bem sucedidos da periferia européia, como Irlanda e Espanha.

\section{Gráfico 4. Mudança estrutural: estamos avançando?}

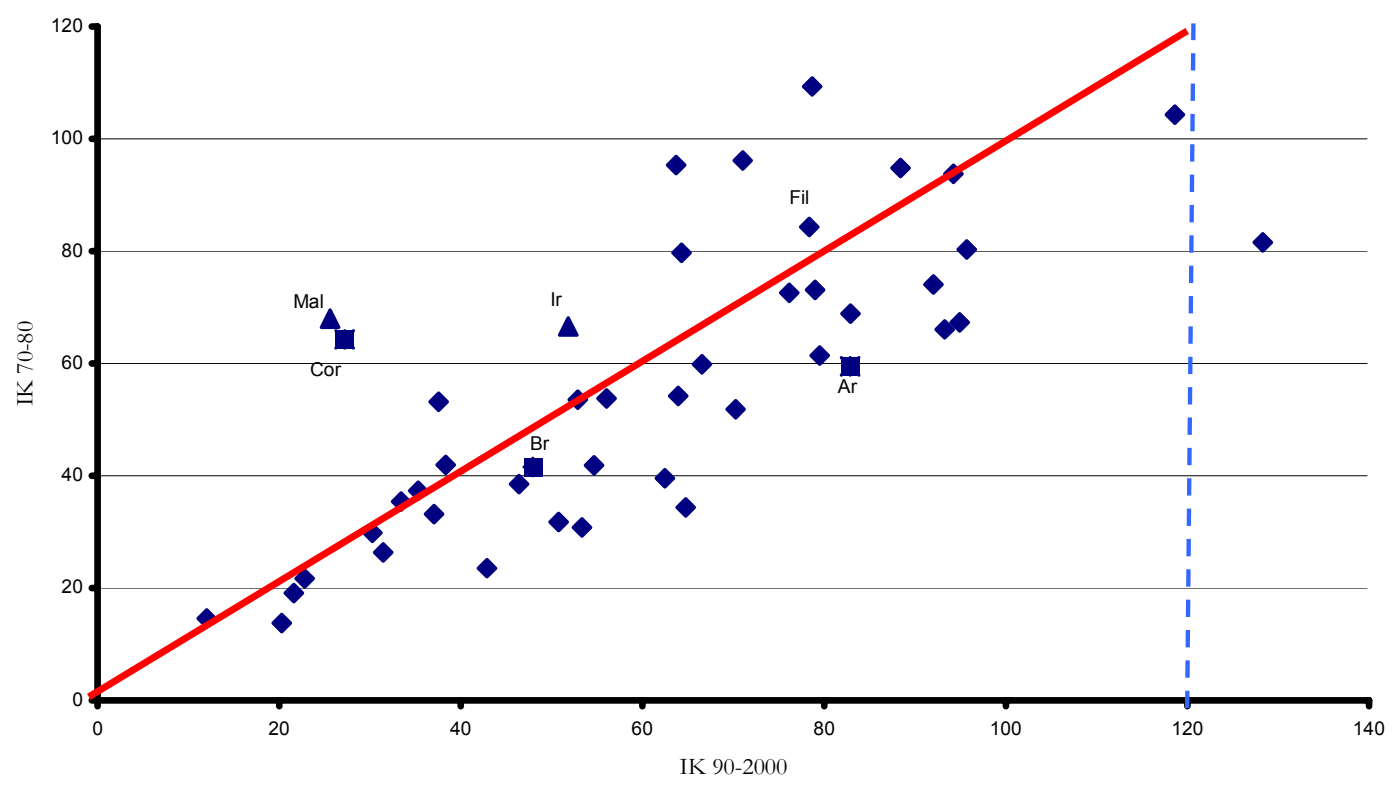

O gráfico 5 confirma essa percepção: as economias asiáticas convergem estruturalmente com o país avançado de referência (Estados Unidos), enquanto que a estrutura industrial do Brasil e de outras economias latino-americanas diverge. 


\section{Gráfico 5. Mudança estrutural: alguns exemplos na América Latina e na Ásia}

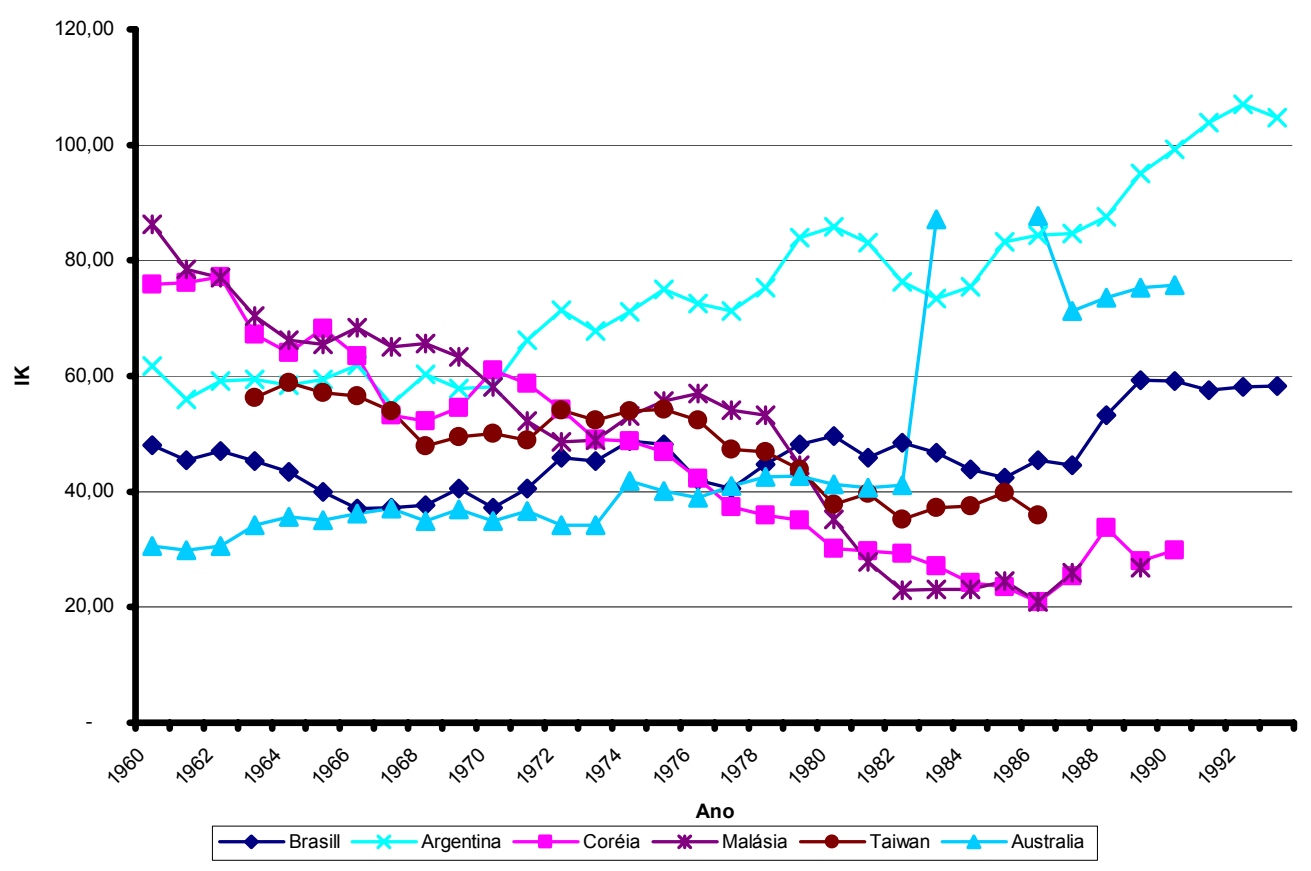

Fonte: os autores a partir de dados da Unido e do World Bank

\section{Comentários Finais}

Uma estrutura industrial diversificada, com forte participação dos setores intensivos em tecnologia, é chave para sustentar a competitividade e o crescimento no longo prazo. Os países que alcançaram convergência de renda per capita no pós-guerra também mostraram convergência na estrutura industrial com as economias mais desenvolvidas. A estrutura industrial brasileira tem evoluído na direção oposta, e esse fato deveria preocupar seriamente os formuladores de política econômica.

\section{Referências Bibliográficas}

ARCHIBUGI, D. E COCCO, A. (2004), "A New Indicator of Technological Capabilities for Developed and Developing Countries”, World Development, 32 (4); 629 -654.

CEPAL (2004), Desarrollo productivo en economias abiertas (LC/G.2234(SES.30/3), documento preparado para el Trigésimo período de sesiones de la CEPAL (San Juan, Puerto Rico, 28 Junio al 2 de Julio), Santiago de Chile.

CIMOLI K., PORCILE, G., PRIMI, A. E VERGARA, S. (2005) “Cambio Estructural, Heterogeneidad Productiva y Tecnología en América Latina”, in M. Cimoli (editor) (2005) Heterogeneidad estructural, asimetrías tecnológicas y crecimiento en América Latina. CEPAL/BID, Santiago de Chile.

UNCTAD (2005) Trade and Development Report 2005: New Features of Global Interdependence. New York and Geneve: United Nations. 